\title{
Improve the Prediction Accuracy of Apple Tree Canopy Nitrogen Content through Multiple Scattering Correction Using Spectroscopy
}

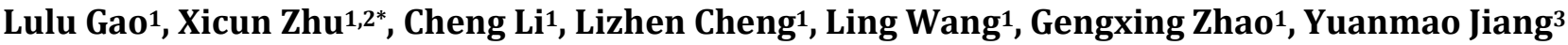 \\ ${ }^{1}$ College of Resources and Environment, Shandong Agricultural University, Taian, Shandong \\ ${ }^{2}$ National Engineering Laboratory on Efficient Utilization of Soil and Fertilization, Taian, Shandong \\ ${ }^{3}$ College of Horticulture Science and Engineering, Shandong Agricultural University, Taian, Shandong \\ Email: *zxc@sdau.edu.cn
}

How to cite this paper: Gao, L.L., Zhu, X.C., Li, C., Cheng, L.Z., Wang, L., Zhao, G.X. and Jiang, Y.M. (2016) Improve the Prediction Accuracy of Apple Tree Canopy Nitrogen Content through Multiple Scattering Correction Using Spectroscopy. Agricultural Sciences, 7, 651-659.

http://dx.doi.org/10.4236/as.2016.710061

Received: September 14, 2016

Accepted: October 18, 2016

Published: October 21, 2016

Copyright $\odot 2016$ by authors and Scientific Research Publishing Inc. This work is licensed under the Creative Commons Attribution International License (CC BY 4.0).

http://creativecommons.org/licenses/by/4.0/

\begin{abstract}
Method: Use Multiple Scattering Correction to eliminate the interference of scattering on spectrum in the process of field measurement so as to improve the accuracy of prediction model of tree canopy nitrogen content. Apple trees in Qixia of Yantai City were taken as the test material. The spectral reflectivity of apple tree canopy went through the First Derivative (FD) and Multiple Scattering Correction (MSC) plus first derivative, respectively. The correlation coefficients were calculated between spectral reflectivity and nitrogen content. The Support Vector Machine (SVM) method was used to establish the prediction model. The result indicates that the MSC pre-processing can improve the correlation between spectral reflectivity and nitrogen content. The SVM model with MSC + FD pre-processing was a good way to predict the nitrogen content. The calibration $\mathrm{R}^{2}$ of the model was 0.746 ; the validation $\mathrm{R}^{2}$ was 0.720 ; and its RMSE was $0.452 \mathrm{~g} \cdot \mathrm{kg}^{-1}$. MSC can commendably eliminate scattering error to improve the prediction accuracy of prediction model.
\end{abstract}

\section{Keywords}

Multiple Scattering Correction, Hyperspectrum, Apple Tree Canopy,

Nitrogen Content, Support Vector Machine

\section{Introduction}

As one of the important elements of plant, nitrogen is the main component composing amino acid, protein, alkaloid, nucleic acid, chlorophyll and is of great importance to the physiological activities of plant [1]. Hyperspectral remote sensing is featured with high 
spectral resolution, continuous waveband and quick measurement. It can be a new method for real-time, fast and lossless apple tree nitrogen estimation [2].

The hyperspectral remote sensing technology was applied to plant field in 1990s. Recently, this technology is being used for the inversion study of nutrient content of wheat [3] [4], corn [5], rice [6] and cotton [7] by scholars from home and abroad. However, Multiple Scattering Correction (MSC) is rarely used in spectral data preprocessing. Multiple Scattering Correction is a kind of spectral reflectivity pre-processing method with scattering elimination function [8]-[12]. MSC was firstly proposed by Martens and others to eliminate the scattering interference due to different sample granularity [13] [14]. Zhao et al. [6] studied the influence of MSC on near infrared spectrum analysis and thought the sample spectral reflectivity was not only related to component content but also subjected to sample particle size, distribution situation and tightness degree. These could be receded through MSC. Huang et al. [8] used MSC to process the hyperspectral reflectivity data of wheat leaves to measure chlorophyll content in wheat leaves. But there are few comparative and analytic researches on whether MSC could improve the accuracy of prediction model.

Therefore, the prediction models were established by taking apple tree as research object in this study. Due to uneven distribution of leaves and branches and various density of canopy in different apple trees, the scattering will therefore disturb spectral information. The original reflectivity was conducted the First Derivative (FD) and Multiple Scattering Correction plus First Derivative (MSC + FD), respectively. The correlation difference was analyzed between the spectral data after the two pre-processings and apple nitrogen content. The prediction models were established of apple tree canopy nitrogen content, respectively. The prediction accuracy was compared to study the influence of MSC. This research aimed at exploring a pre-processing method of hyperspectrum in order to improve the accuracy of prediction model.

\section{Materials and Methods}

\subsection{The Research Area}

The research area is located in Qixia City, Yantai, China, which is known as the "Apple City of China" with the east longitude of $120^{\circ} 33^{\prime}-121^{\circ} 15^{\prime}$ and northern latitude of $37^{\circ} 05^{\prime}-37^{\circ} 32^{\prime}$. The orchard area reaches $4.3 \times 10^{4}$ ha and the main planting variety is Red Fuji apple tree. The temperate zone monsoon subhumid climate brings four distinctive seasons, abundant sunlight, $11.3^{\circ} \mathrm{C}$ average annual temperature, $754 \mathrm{~mm}$ annual precipitation, $2690 \mathrm{~h}$ total sunshine hours and $207 \mathrm{~d}$ annual frost-free period. The terrain is mainly low mountains and hills and agrotype is mainly brown soil [15].

\subsection{Sample Collection and Spectrum Determination}

The test was carried out on September 22, 2014 in Qixia City and the tested apple cultivar is Red Fuji apple. Depending upon the distribution characteristics of orchards, 105 apple trees of 32 orchards in 14 towns were selected as research objects. The determining instrument is Field Spec 4 portable field spectrometer produced by ASD Inc. Wave 
band scope of this instrument is $350-2500 \mathrm{~nm}$, of which, the sampling interval of 350 $1000 \mathrm{~nm}$ is $1.4 \mathrm{~nm}$ and spectral resolution is $3 \mathrm{~nm}$; the sampling interval of $1000-2500$ $\mathrm{nm}$ is $2 \mathrm{~nm}$ and the spectrum resolution is $8 \mathrm{~nm}$. When the weather was sunny, no-cloud, no-wind or of breeze, the reflectivity of canopy was measured at 10:00 14:00. A $5 \mathrm{~m}$ external optical fiber was adopted in the measurement. The optical fiber field angle was $25^{\circ}$ and the probe faced downward vertically. The selection of appropriate determination height was based on the size of the canopy so as to guarantee the whole canopy was in the field of view. Each sample was measured for 10 times and their average value was taken as the value of hyperspectral reflectivity. Standard white plate correction was required every 15 minutes to ensure the measurement accuracy [2].

\subsection{Apple Tree Crown Canopy Nitrogen Determination}

Twelve leaves were collected at each canopy and putted into freshness protection package when measuring. These leaves could be kept in cold and dark place and brought back to laboratory. De-enzyme was conducted for 20 minutes at the dryer with the temperature of $80^{\circ} \mathrm{C}$, then the drying process with $60^{\circ} \mathrm{C}$ was conducted until constant weight was achieved. The dried sample was grinded into powder with mortar and selected by a screen of $0.25 \mathrm{~mm}$. The nitrogen content was determined using the Kjeldahl method.

\subsection{Spectral Data Processing}

The spectrum showed obvious fluctuation at $1350 \mathrm{~nm}, 1850 \mathrm{~nm}$ and $2500 \mathrm{~nm}$ due to the influence of the instrument itself and external environment, especially the moisture in atmosphere. Previous research has found that wave bands highly correlated with nitrogen content are centralized at visible light area. Therefore, the apple tree canopy spectrum of $350-1000 \mathrm{~nm}$ was selected as the research spectral scope based on the wave band characteristic of Field Spec 4 spectrometer to eliminate the interference of external factors such as moisture, etc.

To verify that MSC has effect on the improvement of nitrogen spectral quantitative inversion accuracy, the original spectral reflectivity went through first derivative and multiple scattering correction plus first derivative respectively. The MSC algorithm is as following:

Calculate the average spectrum:

$$
\bar{A}_{j}=\frac{1}{n} \sum_{i=1}^{n} A_{i, j}
$$

Conduct linear regression on spectrum and average spectrum of each sample:

$$
A_{i}=m_{i} \bar{A}+b_{i}
$$

Calculate the corrected spectrum:

$$
A_{i(M S C)}=\frac{\left(A_{i}-b_{i}\right)}{m_{i}}
$$


Of which, $i=1,2, \cdots, \mathrm{n}$ and $\mathrm{n}$ is the number of samples; $j$ means the No. $\mathrm{j}$ of wavelength.

The correlation coefficients were calculated between each wavelength and nitrogen content. The sensitive wavelengths were selected via testing significance to establish the multiple nonlinear regression models through SVM. The effect of MSC was evaluated through analyzing the correlation coefficient ( $r$ ) between spectral data after different pre-processing and nitrogen content and studying the determination coefficient $\left(\mathrm{R}^{2}\right)$ and root mean square error (RMSE) of the model. The model with the highest $R^{2}$ and lowest RMSE was considered the best.

\section{Results and Analysis}

\subsection{The Contrastive Analysis of the Original Spectrum and That after MSC Pre-Processing}

The original reflectance spectral curve was obtained at 350 - $1000 \mathrm{~nm}$ (Figure 1). It can be found that the absolute intensity greatly differed from one another and obvious baseline translation existed at the spectral interval. This was mainly influenced by different canopy structure, light condition, etc. The curve of spectral reflectance characteristics after MSC processing was as shown in Figure 2. The absolute intensity difference reduced significantly, the spectrum was more centralized and the spectral reflection characteristic was more obvious at the same time.

\subsection{Correlation Analysis between Spectral Reflectivity and Nitrogen Content}

The correlation coefficient at each wavelength between the nitrogen content and the raw spectral value and MSC spectral reflectivity, was calculated, respectively (Figure 3). It can be seen from Figure 3 that the correlation coefficients were improved significantly after MSC. At $660 \mathrm{~nm}-683 \mathrm{~nm}$, MSC spectra showed significant correlation

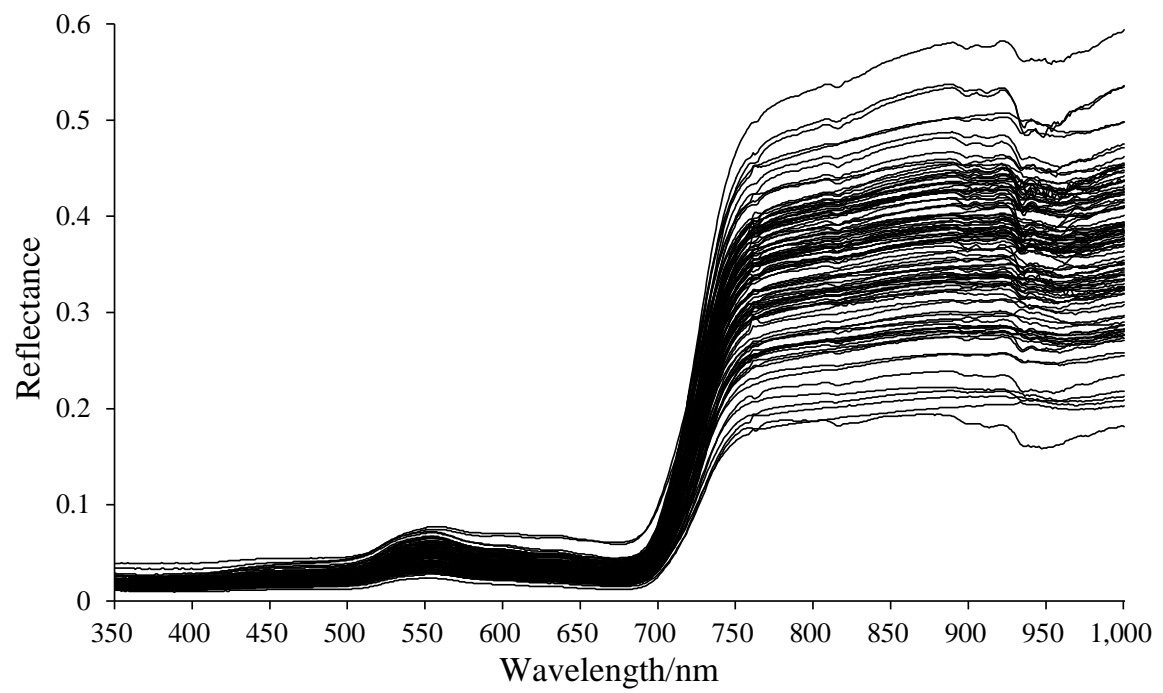

Figure 1. Original spectral reflectance characteristics with different nitrogen concentrations. 


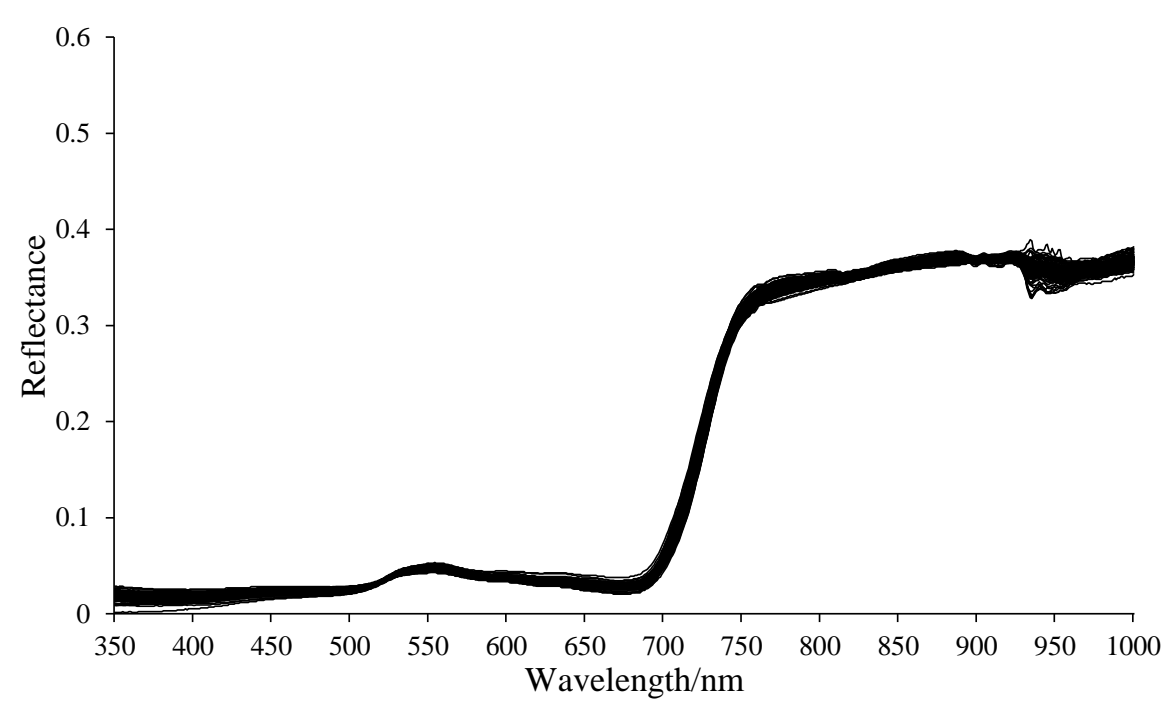

Figure 2. Spectral reflectance characteristics after MSC.

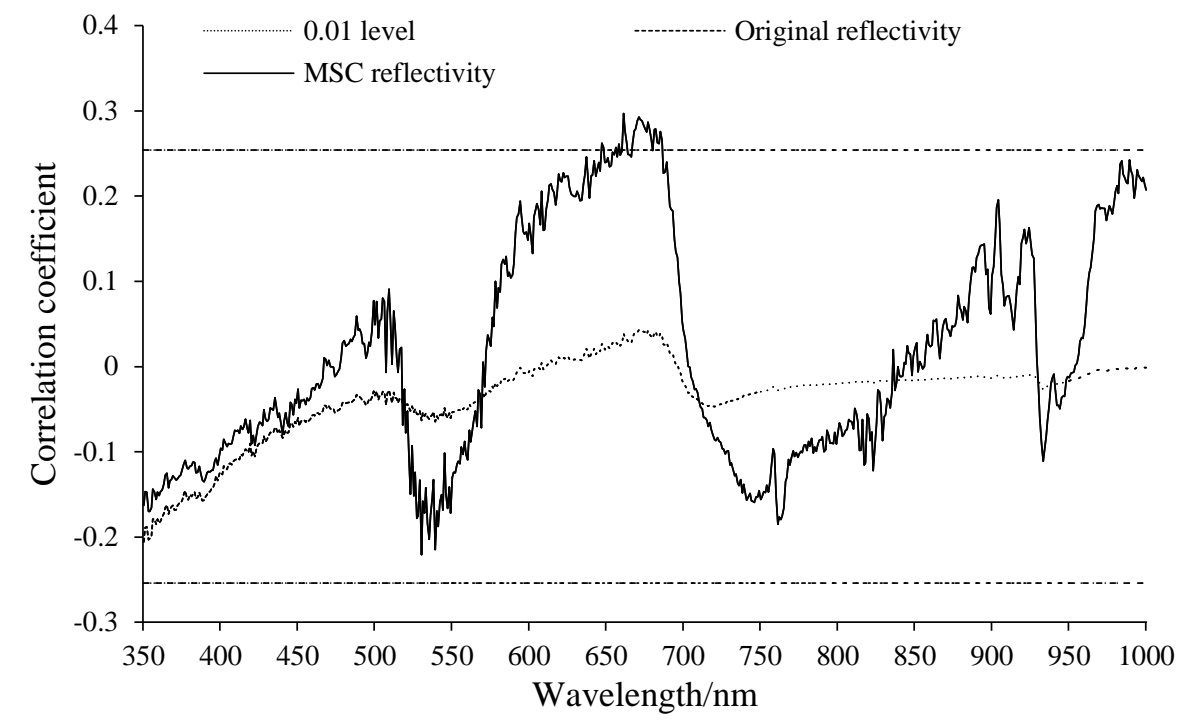

Figure 3. Correlation analysis between spectral reflectivity and the nitrogen content.

with apple tree canopy nitrogen content $(\mathrm{P}<0.01)$.

To further improve the correlation and easier select the sensitive waveband, first derivative processing was applied to the original spectrum and MSC spectrum respectively. As was shown in Figure 4 and Figure 5, the correlation coefficient between FD spectrum and MSC + FD spectrum and nitrogen content showed significant improvement. Meanwhile, the FD correlation coefficients were higher than the MSC + FD correlation coefficients. Of which, 7 wavelengths in FD correlation coefficients reached significant correlation (Figure 4); 12 wavelengths in correlation coefficients in MSC + FD correlation coefficients reached significant correlation (Figure 5).

Table 1 showed the wavelengths with significant correlation between FD spectrum and MSC + FD spectrum and apple tree canopy nitrogen content. It can be seen from 


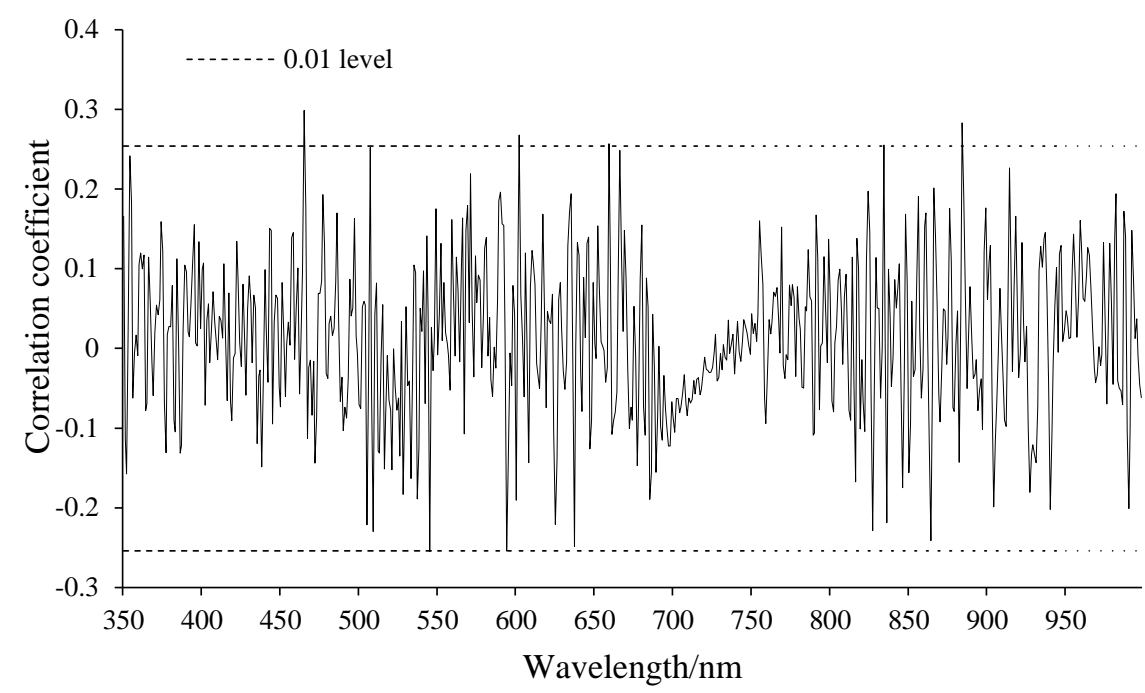

Figure 4. Correlation analysis between FD spectral reflectivity and the nitrogen content.

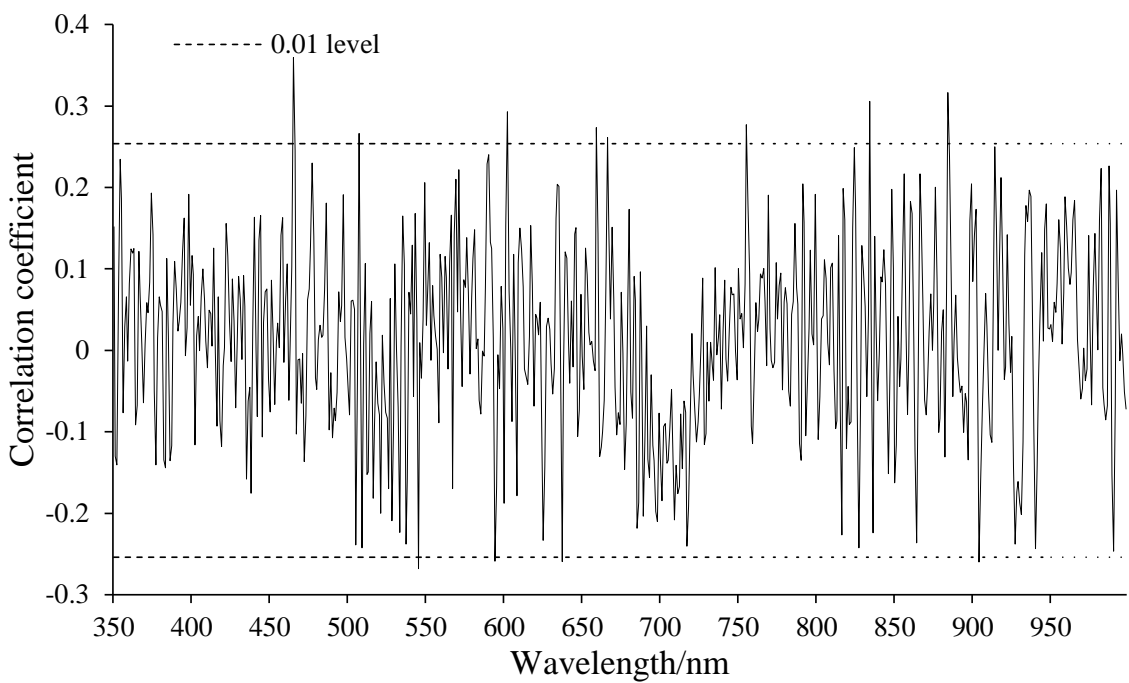

Figure 5. Correlation analysis between MSC + FD spectral reflectivity and the nitrogen content.

Table 1 showed that the FD 7 wavelengths of significant correlation all showed the same in MSC + FD. Moreover, the correlation coefficients of the FD 7 wavelengths were higher than MSC + FD.

\subsection{Establishment and Validation of the Prediction Model}

To compare the prediction accuracy, the same 7 wavelengths were taken as independent variables and apple tree canopy nitrogen contents were taken as dependent variables to the prediction model through SVM method. In the 105 samples, 70 were randomly selected as calibration set and 35 were as prediction set. Samples in calibration set conformed to normal distribution.

SVM parameters were determined after repeated training: penalty coefficient was 1 
Table 1. The wavelengths with significant correlation.

\begin{tabular}{|c|c|c|}
\hline Transformation form & Wavelength/nm & Correlation coefficient \\
\hline \multirow{7}{*}{ FD } & 466 & $0.30^{* *}$ \\
\hline & 546 & $-0.26^{\star *}$ \\
\hline & 595 & $-0.25^{\star *}$ \\
\hline & 603 & $0.27^{\star *}$ \\
\hline & 660 & $0.26^{* *}$ \\
\hline & 835 & $0.26^{\star *}$ \\
\hline & 885 & $0.28^{* *}$ \\
\hline \multirow{12}{*}{$\mathrm{MSC}+\mathrm{FD}$} & 466 & $0.36^{* *}$ \\
\hline & 508 & $0.27^{\star *}$ \\
\hline & 546 & $-0.27^{\star \star}$ \\
\hline & 595 & $-0.26^{\star *}$ \\
\hline & 603 & $0.29^{* *}$ \\
\hline & 638 & $-0.26^{* *}$ \\
\hline & 660 & $0.27^{\star *}$ \\
\hline & 667 & $0.26^{* *}$ \\
\hline & 756 & $0.28^{\star *}$ \\
\hline & 835 & $0.31^{* *}$ \\
\hline & 885 & $0.32^{\star *}$ \\
\hline & 905 & $-0.26^{* *}$ \\
\hline
\end{tabular}

${ }^{* * \mathrm{P}}<0.01$.

and kernel function parameter was 0.6. The modeling and prediction results were as shown in Table 2. The $\mathrm{R}_{\mathrm{c}}^{2}$ with MSC + FD processing compared with FD has risen to 0.746 from 0.624 , and $R_{v}^{2}$ has risen from 0.535 to 0.720 . The $\mathrm{RMSE}_{\mathrm{v}}$ has declined from $0.936 \mathrm{~g} \cdot \mathrm{kg}^{-1}$ to $0.756 \mathrm{~g} \cdot \mathrm{kg}^{-1}$. Therefore, the model based on MSC + FD processing can predict apple tree canopy nitrogen content in a better manner. The MSC processing can improve the accuracy of prediction model.

\section{Conclusion}

Studying the effect of MSC on the accuracy of apple tree canopy nitrogen content prediction model through comparing correlation between reflectivity under the two conversions and nitrogen content, conclusions were as following: 1) the correlation between apple tree canopy spectral reflectivity and nitrogen content was improved significantly after MSC pre-processing; 2) the SVM model with MSC + FD pre-processing served as the optimal method to predict the nitrogen content $\left(\mathrm{R}_{\mathrm{c}}^{2}=0.746, \mathrm{R}_{\mathrm{v}}^{2}=\right.$ 
Table 2. The accuracy of the evaluation models.

\begin{tabular}{cccc}
\hline Transformation form & $\mathrm{R}_{\mathrm{c}}^{2}$ & $\mathrm{R}_{\mathrm{v}}^{2}$ & $\mathrm{RMSE}_{\mathrm{v}} / \mathrm{g} \cdot \mathrm{kg}^{-1}$ \\
\hline FD & 0.624 & 0.535 & 0.936 \\
MSC + FD & 0.746 & 0.720 & 0.452 \\
\hline
\end{tabular}

$\mathrm{R}_{\mathrm{c}}^{2}$ : determination coefficient of calibration; $\mathrm{R}_{\mathrm{v}}^{2}$ : determination coefficient of validation; $\mathrm{RMSE}_{\mathrm{v}}$ : root-mean-square error of validation.

$\left.0.720, \mathrm{RMSE}_{\mathrm{v}}=0.452 \mathrm{~g} \cdot \mathrm{kg}^{-1}\right)$. The model achieved a notably high accuracy and provided the scientific management of the nitrogen content; 3) MSC can commendably eliminate scattering error to improve the prediction accuracy of prediction model.

\section{References}

[1] Peng, F.T., Jiang, Y.M., Gu, M.R. and Shu, H.R. (2003) Effect of Nitrogen on Apple Fruit Hormone Changing Trends and Development. Plant Nutrition and Fertilizer Science, 9, 208-213.

[2] Zhu, X.C., Zhao, G.X., Wang, L., Dong, F., Lei, T. and Zhan, B. (2010) Hyperspectrum Based Prediction Model for Nitrogen Content of Apple Flowers. Spectroscopy and Spectral Analysis, 30, 416-420.

[3] Huang, H., Wang, W., Peng, Y.K., Wu, J.H., Gao, X.D., Wang, X. and Zhang, J. (2010) Measurement of Chlorophyll Content in Wheat Leaves Using Hyperspectral Scanning. Spectroscopy and Spectral Analysis, 30, 1811-1814.

[4] Liang, L., Yang, M.H. and Zang, Z. (2010) Determination of Wheat Canopy Nitrogen Content Ratio by Hyperspectral Technology Based on Wavelet Denoising and Support Vector Regression. Transaction of the CSAE, 26, 248-253.

[5] Daughtry, C.S.T., Walthall, C.L., Kim, M.S., de Colstount, E.B. and McMurtrey III, J.E. (2000) Estimating Corn Leaf Chlorophyll Concentration from Leaf and Canopy Reflectance. Remote Sensing of Environment, 74, 229-239.

[6] Yang, J., Tian, Y.C., Yao, X., Cao, W.X., Zhang, Y.S. and Zhu, Y. (2009) Hyperspectral Estimation Model for Chlorophyll Concentrations in Top Leaves of Rice. Acta Ecology Sinica, 29, 6561-6571.

[7] Huang, C.Y., Wang, D.W., Yan, H., Zhang, Y.X., Cao, L.P. and Cheng, C. (2007) Monitoring of Cotton Canopy Chlorophyll Density and Leaf Nitrogen Accumulation Status by Using Hyperspectral Data. Acta Agronomica Sinica, 33, 931-936.

[8] Centner, V., Verdu-Andres, J., Walczak, B., Jouan-Rimbaud, D., Despagne, F., Pasti, L., Massart, D.-L. and De Noord, O.E. (2000) Comparison of Multivariate Calibration Techniques Applied to Experimental NIR Data Sets. Applied Spectroscopy, 54, 608-623. http://dx.doi.org/10.1366/0003702001949816

[9] Wang, K., Chi, G.Y., Lau, R. and Chen, T. (2011) Multivariate Calibration of Near Infrared Spectroscopy in the Presence of Light Scattering Effect: A Comparative Study. Analytical Letters, 44, 824-836. http://dx.doi.org/10.1080/00032711003789967

[10] Wang, D.M., Ji, J.M. and Gao, H.Z. (2014) The Effect of MSC Spectral Pretreatment Regions on Near Infrared Spectroscopy Calibration Results. Spectroscopy and Spectral Analysis, 34, 2387-2390.

[11] Zhao, Q., Zhang, G.L. and Chen, X.D. (2005) Effects of Multiplicative Scatter Correction on a Calibration Model of Near Infrared Spectral Analysis. Optics and Precision Engineering, 
$13,53-58$.

[12] Xiong, Z.X., Wu, Z.C., Chen, Z.X. and Hu, M.Y. (2007) Application of MSC to the Improvement of Analyzing Accuracy of Fatty Acid in Rapeseed by Near-Infrared Spectroscopy. Chinese Journal of Spectroscopy Laboratory, 24, 953-958.

[13] Geladi, P., Macdougall, D. and Martens, H. (1985) Linearization and Scatter Correction for Near Infrared Reflectance Spectra of Meat. Applied Spectroscopy, 39, 491-500.

http://dx.doi.org/10.1366/0003702854248656

[14] Estienne, F., Despagne, F., Walczak, B., de Noord, O.E. and Massart, D.L. (2004) A Comparison of Multivariate Calibration Techniques Applied to Experimental NIR Data Sets: Part III: Robustness against Instrumental Perturbation Conditions. Chemometrics and Intelligent Laboratory Systems, 73, 207-218. http://dx.doi.org/10.1016/j.chemolab.2004.04.007

[15] Wang, L., Zhao, G.X., Zhu, X.C., Lei, T. and Dong, F. (2010) Quantitative Models between Canopy Hyperspectrum and Its Component Features at Apple Tree Prosperous Fruit Stage. Spectroscopy and Spectral Analysis, 30, 2719-2723.

Submit or recommend next manuscript to SCIRP and we will provide best service for you:

Accepting pre-submission inquiries through Email, Facebook, LinkedIn, Twitter, etc. A wide selection of journals (inclusive of 9 subjects, more than 200 journals)

Providing 24-hour high-quality service

User-friendly online submission system

Fair and swift peer-review system

Efficient typesetting and proofreading procedure

Display of the result of downloads and visits, as well as the number of cited articles

Maximum dissemination of your research work

Submit your manuscript at: http://papersubmission.scirp.org/

Or contact as@scirp.org 